\title{
Studying how Adjustment is Associated with Educational Performance among High-School Girl Students in Andimeshk
}

\author{
Iman Paknejad \\ Faculty member in Farhangian University \\ Paknejad1346@gmail.com
}

\author{
Fatemeh Gramynezhad
}

B.A in consulting and a member of consulting

team of the Education Administration

Andimeshk, Khouzestan, Iran

\begin{abstract}
This paper aims to study how adjustment is associated with the educational performance among high school girl students in Andimeshk. A sample of 300 was randomly clusters in several stages using Bell's adjustment test. Data were analyzed by the correlation significance test in SPSS. Results showed that students' global adjustment was significantly associated with their educational performance at the significance level of $p<0.01$. Moreover, there was also a significant correlation between students' affective adjustment and social adaption ( $p<0.05)$. However, no significant correlation was observed between job adjustment and health adjustment and students educational performance.
\end{abstract}

Keywords: Adjustment, Social, Education, Performance, Educational Progression

\section{INTRODUCTION}

Adjustment, especially social adjustment, is a partial concept varies from nation to nation depending on cultures and beliefs. On the other hand, human's behavior is affected by different factors including family, school, peers, and other social factors. Human personality is perfected when there is an appropriate balance between them and their environment. Social pressures clearly affect behaviors. Being a flexible creature, human being is not only adjusted with the environment, but also revolves the environment according to his/he demands. Therefore, it is crucially important for any living creature to be adjusted with the environment. Human efforts are based on the adjustment. Consciously or unconsciously, any person tries to satisfy his/her various or sometimes contrasting needs where they live (Azin and Moosavi, 2011). Corsini (1999) defines adjustment as a change occurring in attitudes and behaviors in order to effectively and efficiently live. Constructively communicating with others, confronting with troublesome or stressful situation, taking responsibilities, and meeting personal needs and objectives are samples of adjustment (Kazemian Moghadam and Mehrabizadeh Honarmand, 2010).

Adjustment is the ability to incorporate, adapt, compromise, coordinate, and dealing with self, the environment and others. An adjusted person is one mentally healthy. However, fast and compress changes seriously question adjustment resulting in contrast, conflict, stress, and confusion (Saghi and Rajaee, 2009).

Alpourt (1960, quoted by Farahani, 1999) defines social adjustment as having warm and friendly communication. Wazerman (1996) knows social adjustment as a representation of interaction with others, being satisfied of roles, and the way of performing roles probably affected by previous personality and family culture and expectations. To define behavioral adjustment, Williamz (1975) believe that it is an American term referring to people's ability to satisfy the needs of an independent life in a particular society in a socially acceptable way. Social adjustment is a situation in which people or groups progressively and intentionally or unintentionally modifies their behavior in order to be fitted to the existing culture. Behavioral adjustment is reactions shown by people to social environment. They consider them as a behavioral basis due to coordination with social criteria and being accepted.

Studies have revealed that self-awareness, sympathy, responsibility, ability to confront emotions and stress, ability to creatively and critically think, effectively and constructively communicating in interpersonal relationships are of good consequences of training life skills. The improvement of such capabilities develops behavioral adjustments. In a research study by Amidnia et al. (2010) on girl 
students, results disclosed that skills raised personal and social adjustments. Baker (2003) also revealed that the problem-solving skill is an important predictor for students' mental-social adjustment (Tamanaifar and Mansoorinik, 2011).

According to research evidence, educational adjustment is an effective factor in educational progression and success, increased satisfaction and educational life quality. On the other hand, educational non-adjustment may result in depression, loneliness, and reduced educational life quality. Due to the importance of educational adjustment in success and educational progression, researchers have tried to identify factors affecting educational adjustment (Yusefi, Hassani, \& Tahmasebi, 2010).

There are some studies conducted on the adjustment and its relation with educational performance. In a study on the link between creativity and social adjustment and educational performance among high school students in Zanjan City, Abtahi and Nedri concluded that there was a positive and significant correlation between several dimensions, including social adjustment, social context, social skills, family relations, and social relations, and the educational performance. The negative and significant relation is just between antisocial interests and the educational performance (Abtahi and Nedri, 2011).

Basir Shabestari studied the relation between social adjustment and educational progression among dentist students in Ghazvin. They observed no educational progression and social adjustment and the components of socialization and responsibility (Basir Shabestari et al. 2013).

Studying the association between adjustment and the high school students' performance, Sepehri concluded that among the three components of adjustment, the educational component only can predict the educational performance (Sepehri, 2012).

In a research study titled "self-concept, social adjustment and educational success", YengiMaleki, Kalantarkooshe and Maleki Tabar found a positive and significant correlation between social adjustment and educational success (YengiMaleki, Kalantarkooshe and Maleki Tabar, 2005).

Tamanaeifar conducted a research study titled "predicting education progression based on adjustment components among students. They found a significant correlation between education progression, home adjustment, and educational adjustment among girl students (Tamanaeiar and Mansoorinick, 2012).

Conducting a study titled "students' education adjustment", Khodadoost and Karimi saw that there is a significant correlation between educational progression and educational adjustment among girl and boy students (Khodadoost and Karimi, 2010).

Ganai and Mir carried out a study called comparing educational adjustment and educational success among college students. According to them, there is a significant correlation between them (Ganai \& Mohammad Ashraf, 2013).

Adhiambo, Odwar and Mildred prepared a study titled "the relation between adjustment, sex, and educational success among high school students in Kenia". Their findings show a significant correlation between educational adjustment and success (Adhiambo, Odwar, \& Mildred, 2001).

Abdullah et al. found a significant correlation, in their study titled "adjustment among Malaysian students", between adjustment and educational success (Abdullah \& et al., 2009).

Baker emphasized on a significant correlation between educational adjustment and success in their research called "studying social problem solving by adjustment, health, stress, and educational performance" (Baker, 2006).

Yazedjian, Toews and Navarro presented a research study titled "family factors, adjustment and educational progression among students". They found out that the adjustment mediate the relation between family factors and educational success (Yazedjian, Toews, \& Navarro, 2009).

Regarding the results achieved in this regard, this paper struggle to find answers for the following questions and hypotheses.

\section{RESEARCH QUESTIONS}

$>$ Is there any associated between high school girl students' global adjustment and educational performance?

$>$ Is there any associated between high school girl students' health adjustment and educational performance? 
Studying how Adjustment is Associated with Educational Performance among High-School Girl Students in Andimeshk

Is there any associated between high school girl students' affective adjustment and educational performance?

$>$ Is there any associated between high school girl students' job-education adjustment and educational performance?

$>$ Is there any associated between high school girl students' home adjustment and educational performance?

\section{RESEARCH HYPOTHESIS}

$>$ There is an association between high school girl students' global adjustment and educational performance.

$>$ There is an association between high school girl students' health adjustment and educational performance.

$>$ There is an association between high school girl students' affective adjustment and educational performance.

$>$ There is an association between high school girl students' job-education adjustment and educational performance.

$>$ There is an association between high school girl students' home adjustment and educational performance.

Research Methodology: This is a correlational and practical research study.

Research Population: The research population includes all high school girl students in Andimeshk in the academic year 2014-2015.

Research Sample: Research sample includes 300 high school girl student randomly clustered in several stages.

Research Tool: This paper uses two types of tools. First, Bell's adjustment inventory was used to assess adjustment level. Developed in 1961, the test include 160 items scored as Yes or No. the test assesses six adjustment aspects including global adjustment, home adjustment, health adjustment, social adjustment, emotional adjustment, and occupational adjustment. The test was reported as properly valid and reliable. Bell reported the coefficient of reliability between 0.70 and 0.93 . Bahrami (1992) and Abdifard (1995) estimated the coefficient of reliability as 0.89 and 0.88 respectively. Low scores represent higher adjustment (Fathi Ashtiani \& Dastani, 2009). Second, their mid-term averages were used to assess performance.

\section{RESEARCH FINDINGS}

Table1. Descriptive Statistics Relating To Students' Adjustment

\begin{tabular}{|c|c|c|c|c|}
\hline Statistic Indices & Adjustment Situation & Number & Mean & Standard Deviation \\
\hline \multicolumn{2}{|l|}{ Home Adjustment } & 300 & 7 & 5.4 \\
\hline \multicolumn{2}{|l|}{ Health Adjustment } & 300 & 5.5 & 4.8 \\
\hline \multicolumn{2}{|l|}{ Social Adjustment } & 300 & 10.5 & 5.2 \\
\hline \multicolumn{2}{|c|}{ Emotional Adjustment } & 300 & 7 & 7.4 \\
\hline \multicolumn{2}{|c|}{ Occupational Adjustment } & 300 & 8.5 & 6.2 \\
\hline \multicolumn{2}{|l|}{ Global adjustment } & 300 & 38.5 & 18.30 \\
\hline
\end{tabular}

According to above table, the lowest and highest mean values of adjustment respectively relate to health adjustment (5.5) and social adjustment (10.5). Additionally, the highest and lowest standard deviations were reported respectively for health adjustment (6.2) and social adjustment (4.8). Mean and standard deviation for the global adjustment were also estimated at 38.5 and 18.30.

There is an association between high school girl students' global adjustment and educational performance.

Table2. Findings Relating To the Association between Global Adjustment and Educational Performance

\begin{tabular}{|c|c|c|c|c|c|}
\hline \multirow{2}{*}{$\begin{array}{l}\text { Criterion } \\
\text { Variable }\end{array}$} & \multirow{2}{*}{$\begin{array}{l}\text { Predictor } \\
\text { Variable }\end{array}$} & \multicolumn{4}{|c|}{ Global Adjustment } \\
\hline & & Number & $\begin{array}{l}\text { Correlation } \\
\text { Coefficient } \\
\end{array}$ & $\begin{array}{l}\text { Degree of } \\
\text { Freedom }\end{array}$ & $\begin{array}{l}\text { Significance } \\
\text { Level }\end{array}$ \\
\hline \multicolumn{2}{|c|}{ Educational Performance } & 300 & 0.45 & 298 & $\mathrm{P} *<0.01$ \\
\hline
\end{tabular}


Table 2 shows the correlation coefficient between the global adjustment and educational performance at $0.45(\mathrm{r}=0.45)$. This is significant at the probability level of less than $\mathrm{p}<0.01$. Therefore, the global performance is significantly associated with students' educational performance.

Second Hypothesis: There is an association between high school girl students' health adjustment and educational performance.

Table3. Findings Relating To the Association between Social Adjustment and Educational Performance

\begin{tabular}{|l|l|l|l|l|l|}
\hline $\begin{array}{l}\text { Criterion } \\
\text { Variable }\end{array}$ & $\begin{array}{l}\text { Predictor } \\
\text { Variable }\end{array}$ & \multicolumn{3}{|l|}{ Social Adjustment } \\
\cline { 3 - 6 } & Number & $\begin{array}{l}\text { Correlation } \\
\text { Coefficient }\end{array}$ & $\begin{array}{l}\text { Degree } \\
\text { Freedom }\end{array}$ & $\begin{array}{l}\text { Significance } \\
\text { Level }\end{array}$ \\
\hline Educational Performance & 300 & 0.36 & 298 & $\mathrm{P}^{*}<0.01$ \\
\hline
\end{tabular}

Table 3 shows the correlation coefficient between the social adjustment and educational performance at $0.36(\mathrm{r}=0.45)$. This is significant at the probability level of less than $\mathrm{p}<0.01$. Therefore, the global performance is significantly associated with students' educational performance.

Third Hypothesis: There is an association between high school girl students' health adjustment and educational performance.

Table4. Findings Relating To the Association between Social Adjustment and Educational Performance

\begin{tabular}{|l|l|l|l|l|l|}
\hline $\begin{array}{l}\text { Criterion } \\
\text { Variable }\end{array}$ & $\begin{array}{l}\text { Predictor } \\
\text { Variable }\end{array}$ & Health Adjustment & $\begin{array}{l}\text { Significance } \\
\text { Level }\end{array}$ \\
\cline { 3 - 6 } & Number & $\begin{array}{l}\text { Correlation } \\
\text { Coefficient }\end{array}$ & $\begin{array}{l}\text { Degree of } \\
\text { Freedom }\end{array}$ & P $>0.05$ \\
\hline Educational Performance & 300 & 0.12 & 298 & \\
\hline
\end{tabular}

Table 3 shows the correlation coefficient between the social adjustment and educational performance at $0.12(\mathrm{r}=0.12)$. This is significant at the probability level of less than $\mathrm{p}<0.01$. Therefore, the global performance is significantly associated with students' educational performance.

Forth Hypothesis: There is an association between high school girl students' affective and educational adjustment and educational performance.

Table5.Findings Relating To the Association between Affective Adjustment and Educational Performance

\begin{tabular}{|l|l|l|l|l|l|}
\hline $\begin{array}{l}\text { Criterion } \\
\text { Variable }\end{array}$ & $\begin{array}{l}\text { Predictor } \\
\text { Variable }\end{array}$ & Affective Adjustment & $\begin{array}{l}\text { Significance } \\
\text { Level }\end{array}$ \\
\cline { 3 - 6 } & Number & $\begin{array}{l}\text { Correlation } \\
\text { Coefficient }\end{array}$ & $\begin{array}{l}\text { Degree of } \\
\text { Freedom }\end{array}$ & P*<0.01 \\
\hline \multicolumn{2}{|l|}{ Educational Performance } & 300 & 0.26 & 298 & \\
\hline
\end{tabular}

Table 5 shows the correlation coefficient between the affective adjustment and educational performance at $0.26(\mathrm{r}=0.26)$. This is significant at the probability level of less than $\mathrm{p}<0.01$. Therefore, the global performance is significantly associated with students' educational performance.

Fifth Hypothesis: There is an association between high school girl students' job adjustment and educational performance.

Table6. Findings Relating To the Association between Job Adjustment and Educational Performance

\begin{tabular}{|c|c|c|c|c|c|}
\hline \multirow{2}{*}{$\begin{array}{l}\text { Criterion } \\
\text { Variable }\end{array}$} & \multirow{2}{*}{$\begin{array}{l}\text { Predictor } \\
\text { Variable }\end{array}$} & \multicolumn{4}{|c|}{ Job Adjustment } \\
\hline & & Number & $\begin{array}{l}\text { Correlation } \\
\text { Coefficient }\end{array}$ & $\begin{array}{l}\text { Degree of } \\
\text { Freedom }\end{array}$ & $\begin{array}{l}\text { Significance } \\
\text { Level }\end{array}$ \\
\hline \multicolumn{2}{|c|}{ Educational Performance } & 300 & 0.10 & 298 & $\mathrm{P}<0.05$ \\
\hline
\end{tabular}

Table 6 shows the correlation coefficient between the social adjustment and educational performance at $0.10(\mathrm{r}=0.10)$. This is not significant at the probability level of less than $\mathrm{p}<0.05$. Therefore, the global performance is not significantly associated with students' educational performance.

Sixth Hypothesis: There is an association between high school girl students' home adjustment and educational performance.

Table7. Findings Relating To the Association between Home Adjustment and Educational Performance

\begin{tabular}{|l|l|l|l|l|l|}
\hline Criterion & Predictor & Job Adjustment & \multicolumn{4}{|l|}{$\begin{array}{l}\text { Segree of } \\
\text { Variable }\end{array}$} & Variable & Fumber & $\begin{array}{l}\text { Correlation } \\
\text { Coefficient }\end{array}$ & $\begin{array}{l}\text { Significance } \\
\text { Level }\end{array}$ \\
\cline { 3 - 6 }
\end{tabular}




\begin{tabular}{|l|l|l|l|l|}
\hline \hline Educational Performance & 300 & 0.14 & 298 & $\mathrm{P} *<0.05$ \\
\hline
\end{tabular}

Table 7 shows the correlation coefficient between the social adjustment and educational performance at $0.14(\mathrm{r}=0.14)$. This is significant at the probability level of less than $\mathrm{p}<0.05$. Therefore, the global performance is significantly associated with students' educational performance.

\section{RESUlTS}

This paper aims to study how adjustment is associated with the educational performance among high school girl students in Andimeshk. A sample of 300 were randomly clusters in several stages. Results include:

$>$ There is a correlation (0.45) between global adjustment and the educational performance among students. This value is significant at the probability level of smaller than 0.01 . Thus, there is a significant correlation between the global adjustment and the educational performance.

$>$ There is a correlation (0.36) between social adjustment and the educational performance among students. This value is significant at the probability level of smaller than 0.01 . Thus, there is a significant correlation between the social adjustment and the educational performance.

$>$ There is a correlation (0.12) between health adjustment and the educational performance among students. This value is significant at the probability level of smaller than 0.05 . Thus, there is a significant correlation between the health adjustment and the educational performance.

$>$ There is a correlation (0.26) between affective adjustment and the educational performance among students. This value is significant at the probability level of smaller than 0.01 . Thus, there is a significant correlation between the affective adjustment and the educational performance.

$>$ There is a correlation (0.14) between home adjustment and the educational performance among students. This value is significant at the probability level of smaller than 0.05 . Thus, there is a significant correlation between the home adjustment and the educational performance.

$>$ There is a correlation (0.10) between job adjustment and the educational performance among students. This value is significant at the probability level of smaller than 0.05 . Thus, there is a significant correlation between the job adjustment and the educational performance.

\section{DisCuSSION}

Our results agree with some and do not agree with some other studies. Our findings are inconsistent with what Ganay and Mir (2013), Adhiambo, Odvar and Milderd (2011), Abdollah et al. (2009), Beyker (2006), Yazdjian, Tooz and Navaro (2009), Abtahi and Nedri (2011), Sepehri, Rahmani and Ghramolki (2012), Yengi Molki, Kalantarkooshe and Maleki Tabar (2005), Tamanayeefar and Mansoorinik (2011), Khodadoost and Karimi (2010) have found out. This shows that adjustment has an important role in life, especially in education. The reason is that if students have the ability to adjust, they can gradually solve their educational problems and succeed. However, our results do not agree with findings presented by Basir Shabestari et al. (2012), because of different sociology, different tools applied for gathering information, and different cultural and social conditions.

\section{REFERENCES}

Abdullah, M. C., \& etal. (2009). Adjustment amongst first students in a Malaysian university. European Journal of Social Sciences, 8(3), 496-505 .

Adhiambo, W. M., Odwar, A. J., \& Mildred, M. (2001). The Relationship among School Adjustment, Gender and Academic Achievement amongst Secondary School Students in Kisumu District Kenya. Journal of Emerging Trends in Educational Research and Policy Studies (JETERAPS), 2 (6)(493-497 .)

Baker, S. R. (2006). A prospective longitudinal investigation of social problem solving appraisals on adjustment to university, stress, health, and academic motivation and performance. Personality and Individual Differences, 35, 569-591

Ganai, M. Y., \& Mohammad Ashraf, M. (2013). A comparative study of adjustment and academic achievement of college students. Journal of Educational Research and Essays, 1(1), 5-8 . 
Yazedjian, A., Toews, M. L., \& Navarro, A. (2009). Exploring Parental Factors, Adjustment, and Academic Achievement Among White and Hispanic College Students. Journal of College Student Development, 50

Abtahi, M., Nedri, Kh. (2011), the association between social creativity and adjustment and high school students' educational performance in Zanjan, education management, second

Azin, A., \& Moosavi, S., M., (2011), investigating the role of educational factors on social adjustment of high school students in Dreydoonshahr City, applied sociology, first

Basir Shabestari, S., V, et al. (2013), investingating the relation between social adjustment and educational progression among dentist students in Ghazvin, educational development in medical sciences, $11,10-11$

Tamanaei far, M., R., Mansoori Nik, A., (2002), predicting the educational progression based on adjustment components among behavioral sciences students, 25 .

Khodadoos, M., Karimi, R., (2010), students' adjustment, paper presented at the fifth conference of mental health, Tehran.

Saghi, M., H., \& Rajaei, 2009, relation between the adaloscenses' perception of family performance with their adjustment, Attitude and Behavior, 10, 82-71

Fathi Ashtiani, A., Dastani, ., (2009), psychological Tests, Tehran, Besat

Kazemian Moghadam, K, and Mehrabi zade Honarmand, M., (2010), comparing the religious attitude and mental health among girl and boy students in Behbahan Islamic Azad University, psychology and religion, second, 173-187

Kalantar Gushe, S. Yengi Maleki, S., \& Maleki Tabar, A., (2005), the concept of self and social adjustment and students' educational success, human and social sciences, 8

Yusefi, B., Hasani, Z, \& Tahmasebi, V., (2010), investigating factors relating to students' educational adjustments in physical education, Iran, Journal of sport management studies, 26, 13-26 